\title{
Flexible Powder Production for Additive Manufacturing of Refractory Metal-Based Alloys
}

\author{
Frauke Hinrichs ${ }^{1} \mathbb{1}$, Alexander Kauffmann ${ }^{1, * \mathbb{C}}$, Daniel Schliephake ${ }^{1}$, Sascha Seils ${ }^{1}$, Susanne Obert ${ }^{1}$, \\ Karin Ratschbacher ${ }^{2}$, Melissa Allen ${ }^{2}$, Astrid Pundt ${ }^{1}$ and Martin Heilmaier ${ }^{1}{ }^{(0)}$ \\ 1 Institute for Applied Materials (IAM-WK), Karlsruhe Institute of Technology (KIT), \\ Engelbert-Arnold-Straße 4, 76131 Karlsruhe, Germany; frauke.hinrichs@kit.edu (F.H.); \\ daniel.schliephake@kit.edu (D.S.); sascha.seils@kit.edu (S.S.); susanne.obert@wieland.com (S.O.); \\ astrid.pundt@kit.edu (A.P.); martin.heilmaier@kit.edu (M.H.) \\ 2 GfE Metalle und Materialien GmbH, Höfener Str. 45, 90431 Nürnberg, Germany; \\ karin.ratschbacher@gfe.com (K.R.); melissa.allen@gfe.com (M.A.) \\ * Correspondence: alexander.kauffmann@kit.edu
}

check for updates

Citation: Hinrichs, F.; Kauffmann, A.; Schliephake, D.; Seils, S.; Obert, S.;

Ratschbacher, K.; Allen, M.; Pundt, A.; Heilmaier, M. Flexible Powder

Production for Additive

Manufacturing of Refractory

Metal-Based Alloys. Metals 2021, 11,

1723. https://doi.org/10.3390/

met11111723

Academic Editor: Michael E. Kassner

Received: 20 September 2021

Accepted: 23 October 2021

Published: 28 October 2021

Publisher's Note: MDPI stays neutral with regard to jurisdictional claims in published maps and institutional affiliations.

Copyright: (c) 2021 by the authors. Licensee MDPI, Basel, Switzerland. This article is an open access article distributed under the terms and conditions of the Creative Commons Attribution (CC BY) license (https:/ / creativecommons.org/licenses/by/ $4.0 /)$.

\begin{abstract}
The quality and properties of metal powders are essential for powder metallurgical (PM) processes in general and for additive manufacturing (AM) processing routes in particular. Thus, a variety of atomization technologies were established meeting the multiple needs of the different processing technologies. However, the production of refractory metal alloy powder remains challenging due to their high liquidus temperatures $\left(>2000^{\circ} \mathrm{C}\right)$, the formation of brittle intermetallic phases, as well as the reactivity with and sensitivity to interstitials of the constituting elements. In this contribution, powders made of Mo-20Si-52.8-Ti (at.\%) were produced by a novel ultrasonic atomization (UA) process at laboratory-scale using an industrial electrode induction gas atomization (EIGA) process with a modified electrode concept for the first time. UA allows flexibility in alloy composition due to the arc melting-based principle, while the EIGA electrode is PM manufactured from elemental powders to provide similar flexibility on a larger scale. The powders resulting from these two processes were compared with respect to size distribution, sphericity, microstructure and phase constitution, chemical composition, and interstitial impurity content. In addition, several powder batches were produced with the UA process in order to assess the process reliability and stability. The properties, quality, and quantities of UA powders perfectly meet the requests for alloy development for powder bed fusion AM, while the modified EIGA process allows the upscaling of the alloy powder quantities.
\end{abstract}

Keywords: additive manufacturing; powder properties; refractory metal alloy; molybdenum silicides; Mo-Si-Ti; ultrasonic atomization; gas atomization

\section{Introduction}

Since its beginnings in the field of rapid prototyping, powder bed fusion additive manufacturing (AM) techniques have reached broad industrial acceptance and are now increasingly used for the series production of components in medical and aerospace industries. Currently, however, the mainly existing wrought and cast alloy compositions are used, which are already established in conventional manufacturing technology [1-4]. The main advantage of AM is the freedom in geometric design, which is increasingly used for structural optimization of lightweight components. Beyond this, AM additionally opens up another field of potential applications. Near-net shape manufacturing might be used to produce components from materials that, due to their property profile, cannot be machined or deformed into required shapes conventionally. Yet, the number of alloy variations that have been deliberately designed for this purpose is still limited. Despite this huge potential, one reason why new alloy developments for AM are progressing rather slowly is that even the production of the alloy powders in these cases is challenging. 
Furthermore, available powder production methods often do not provide powders that fulfil the properties that AM requires concerning flowability, sphericity, interstitial element content, humidity, etc. [4].

Hence, we proposed an approach for flexible, quick, and cost-efficient alloy powder development at laboratory-scale by utilizing a novel ultrasonic atomization (UA) process and its upscaling to a standard atomization process of composite electrodes by electrode induction gas atomization (EIGA). Figure 1a shows the principle of UA with the ATOLab+ machine (3DLab Ltd., Warsaw, Poland) used in the present study. For UA, a plasma arc is ignited between the $\mathrm{W}$ electrode and the water-cooled crucible, which is placed on the sonotrode. The crucible is composed of an outer $\mathrm{Cu}$ ring and an insert made of a refractory metal. The metal feed rod, which is made utilizing standard laboratory scale arc melting [5], is gradually melted by the plasma arc to create a melt pool on the vibrating crucible. The ultrasonic vibration causes droplets to separate from the melt pool, which are carried away by an inert gas flow. Subsequently, in this study, the EIGA principle was applied as shown in Figure $1 \mathrm{~b}$ for a proof of concept with respect to upscaling by gas atomization. Since the brittle nature of refractory metal silicides limits the ability to cast electrodes [6], the alloy electrode was made via powder metallurgy (PM) from elemental powders. The machined tip is then induction heated and melted to a stream falling through a nozzle. The melt is subsequently hit by a high-impact gas flow, which breaks the melt flow into small droplets. A more detailed description as well as a detailed assessment of the EIGA process compared to other atomization methods with regards to the processing of reactive alloys with high liquidus temperatures is provided by Gerling et al. in Ref. [7].

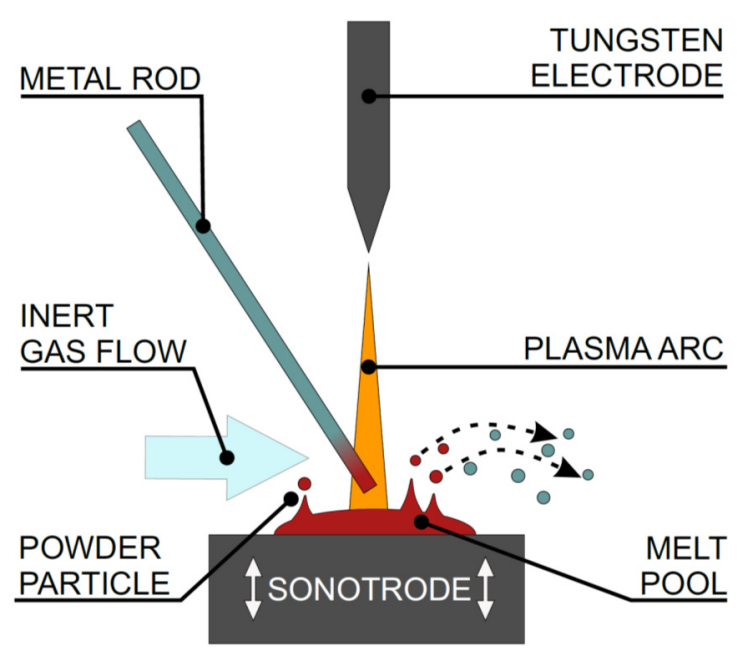

(a)

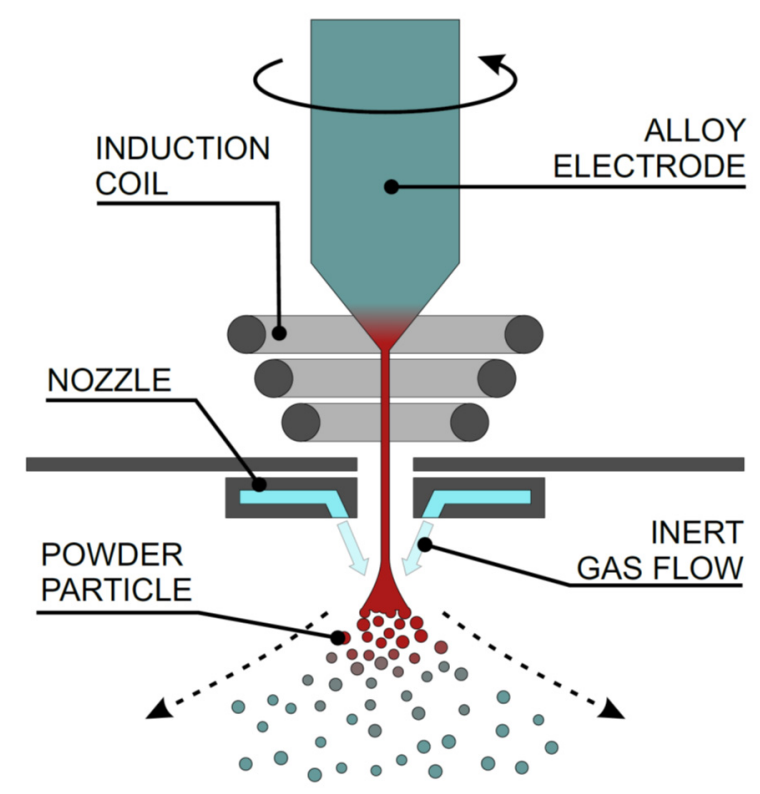

(b)

Figure 1. Schemes of UA (a) and EIGA (b).

The successful scaling of the proposed processes is exemplified with a eutectic refractory metal silicide alloy, namely Mo-20Si-52.8Ti (at.\%). The significant reactivity with oxygen and the generally high brittle-to-ductile transition temperatures of Mo-Si-based alloys beyond $800^{\circ} \mathrm{C}$ [8] are making manufacturing prone to contamination problems in established PM processes. On the positive side, it provides exceptional oxidation resistance [9] at intermediate temperatures, which is rarely observed for high-Mo-containing alloys [8]. In conjunction with an exceptionally low density below state-of-the-art Ni base superalloys, $\left(6.25 \mathrm{~g} / \mathrm{cm}^{3}\right.$ vs. $9.5 \mathrm{~g} / \mathrm{cm}^{3}$ [9]) it may thus be a promising candidate for high-temperature structural applications. Due to a eutectic solidification in an extended temperature interval from $1930^{\circ} \mathrm{C}$ down to $1720^{\circ} \mathrm{C}$ in thermodynamic equilibrium, it is 
suitable for powder bed fusion AM techniques. However, reactivity of the participating elements and brittleness of the bulk alloy restricts application of commonly available PM techniques.

The powders were compared with respect to their chemical composition, particle shape, and size distribution in order to assess the potential of the novel UA technique and the adopted EIGA approach for alloy powder development. Since no information about process stability during US atomization of reactive and high-melting alloys is publicly available, the powders gained with this method were evaluated with respect to process stability by manufacturing and analysis of several individual batches. For the assessment of bulk properties of the manufactured powders, field-assisted sintered microstructures were investigated.

\section{Materials and Methods}

\subsection{Sample Synthesis}

Pure Mo (99.95\%, EVOCHEM, Offenbach am Main, Germany), Ti (99.8+\%, ChemPUR, Karlsruhe, Germany) and $\mathrm{Si}(99.99 \%$ ChemPUR) were weighed in according to the composition of Mo-20Si-52.8Ti (at.\%). Three ingots were arc melted in a water-cooled Cu crucible by utilizing an AM/0.5 arc melter (Edmund Bühler $\mathrm{GmbH}$, Bodelshausen, Germany). The chamber was evacuated to a pressure of $5 \times 10^{-2}$ mbar and flooded with Ar three times before pumping to a high vacuum of less than $1 \times 10^{-4}$ mbar. The buttons were re-melted five times to ensure homogeneity. Subsequently, the ingots were cast into rods of $10 \mathrm{~mm}$ in diameter and a typical length of $150 \mathrm{~mm}$.

The rods were atomized via UA in an ATOLab+ (3DLab Ltd., Warsaw, Poland). The chamber was evacuated and then flooded with Ar of $>99.998 \%$ purity. A crucible with a Ti insert was used. The machine was operated at a vibration frequency of $35 \mathrm{kHz}$ and an amplitude of $60 \%$ as well as an arc current of $160 \mathrm{~A}$. The Ar flow was set to $25 \mathrm{~L} / \mathrm{min}$. The powders from each rod were kept separately in order to assess process stability and reproducibility. Each powder batch was sieved in an Ar filled glove box with a $-100 \mu \mathrm{m}$ mesh size.

EIGA powder was produced by GfE Metalle und Materialien GmbH (Nürnberg, Germany). For detailed technical data on their EIGA device, we refer to Ref. [10]. Due to the aforementioned brittle nature of the Mo-20Si-52.8Ti alloy, the EIGA electrode was manufactured through a PM process. Powders of pure Mo and Ti as well as of a SiTialloy were mixed to achieve a homogeneous powder mixture. For mixing, a tumbler mill with $6 \mathrm{~L}$ in volume was used. The mixture was then enclosed in a Ti-capsule and consolidated through hot isostatic pressing (HIP) into a rod shape with pressures in the range of 100-150 bar at a temperature below the onset temperature of the exothermal phase formation. The average diameter of the electrode was between $50-70 \mathrm{~mm}$. The rod was machined to achieve the required shape for EIGA. Alloy formation to the target composition was achieved in-situ during induction melting of the electrode tip right before atomization. The EIGA powder was also sieved in an Ar-filled glove box with a $-100 \mu \mathrm{m}$ mesh size.

For the assessment of the bulk properties, $15 \mathrm{~g}$ of powder from each manufacturing route were sintered through field-assisted sintering (FAST) in a Typ HP D device (FCT Systeme GmbH; Rauenstein, Germany). Cylindrical pellets of $20 \mathrm{~mm}$ in diameter were made with temperature ramps of $100 \mathrm{~K} / \mathrm{min}$, applied stresses of $50 \mathrm{MPa}$, and maximum temperatures of 1200 or $1300^{\circ} \mathrm{C}$, both for a dwell time of $5 \mathrm{~min}$.

\subsection{Material Analysis}

Backscattered electron (BSE) contrast images were obtained on cross sections of the as-cast material, the powder particles (US and EIGA powders), and the FAST samples. The embedded samples were ground using SiC paper up to grit P2500, followed by 3 and $1 \mu$ polishing steps. The surface finish was achieved by polishing with a colloidal OP-S suspension (Buehler ITW, Esslingen am Neckar, Germany). Au thin films were 
deposited onto the powder samples in order to ensure electrical contact for further SEM inspection. For particle analysis, images of the particle morphology were taken in BSE mode, after placing some powder on an adhesive $C$ pad. BSE imaging was performed on Zeiss EVO50 or Leo 1530 scanning electron microscopes (SEM, Carl Zeiss AG, Oberkochen, Germany). The BSE images of powder particles were binarized using the open source software ImageJ, version $1.53 \mathrm{c}$ and individual particle shapes were approximated by ellipsoids. The maximum and minimum diameters of the ellipsoids as well as their aspect ratios were calculated using ImageJ. Similarly, the porosity of the consolidated powder samples was calculated by areal analysis in ImageJ, using binarized micrographs of the respective samples. Inductively coupled plasma optical emission spectrometry (ICP-OES) was used to track changes in the alloy composition throughout the process steps of each UA sample batch, as well as to determine if the target composition of the EIGA powder was met. For sample preparation, microwave-assisted acid digestion was used. Three measurements were performed for each sample. Interstitial $\mathrm{O}$ and $\mathrm{N}$ content were tracked by means of carrier gas hot extraction (CGHE) on a Leco TC600 device (Mönchengladbach, Germany), using an Ni flux agent and an analysis current of $880 \mathrm{~A}$. At least three measurements were performed for each sample. To determine the phases present, X-ray diffraction (XRD) analyses were carried out using a D2 Phaser system (Bruker, Billerica, MA, USA) equipped with a LynxEye line detector (Bruker, Billerica, MA, USA). Analyses were conducted at a step size of $0.01^{\circ}$. The device was set up in Bragg-Brentano geometry with $\mathrm{Cu} \mathrm{K} \alpha$ radiation. The $\mathrm{Cu}$ tube was operated at $30 \mathrm{kV}$ and $10 \mathrm{~mA}$. The according radiation was filtered by means of an Ni foil.

\section{Results}

\subsection{UA Powder}

From rods with an initial weight of $40-50 \mathrm{~g}, 45-50 \mathrm{wt} . \%$ of the input rods were atomized to powder particles with diameters of $<100 \mu \mathrm{m}$. Approximately $15 \mathrm{~mm}$ of the rod (15-20 g) were used for mounting to the feeding system. A BSE micrograph of the UA powder is shown in Figure 2a. The particles appeared spherical and were free of satellite particles. A respective micrograph of the EIGA powder particles is shown in Figure $2 b$ but will be discussed in Section 3.2. The particle size distributions of three individual UA powders batches (S1 to S3) are depicted in Figure 3a in cumulative frequency (upper graph) and in relative frequency (lower graph). It shall be noted that due to the analysis of BSE images, the frequencies refer to the number count of the particles. Multiple powder batches were analysed in order to investigate the UA process reliability and reproducibility. The particle size distributions of the three UA powder batches showed good reproducibility. Above $85 \%$ of the powder particles were in the narrow range of 40 and $80 \mu \mathrm{m}$ in diameter. Less than $6.4 \%$ of the particles had diameters below $40 \mu \mathrm{m}$, and only a very small fraction of less than $0.2 \%$ were fine particles below $20 \mu \mathrm{m}$. The $\mathrm{d}_{90}$-values were similar across the individual batches with 63, 72, and $78 \mu \mathrm{m}$ for S1, S2, and S3, respectively. Additionally, the particles' aspect ratio analysis is depicted in Figure 3b. The UA powder particles exhibit very good sphericity, with more than $90 \%$ of all particles having an aspect ratio of less than 1.2. Both a narrow size distribution as well as a spherical particle morphology contributed largely to good powder flowability [4], which is essential for the powder layer preparation during powder bed fusion AM. 


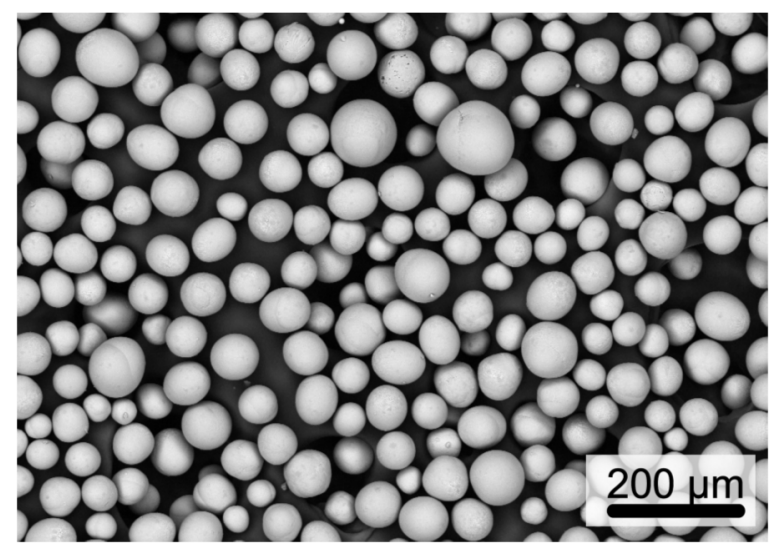

(a)

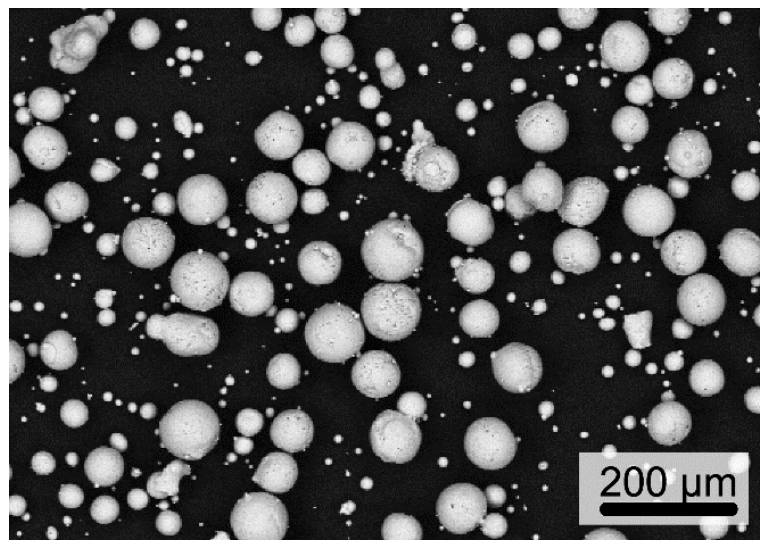

(b)

Figure 2. SEM BSE topography images of UA powder particles (a) and EIGA powder particles (b).

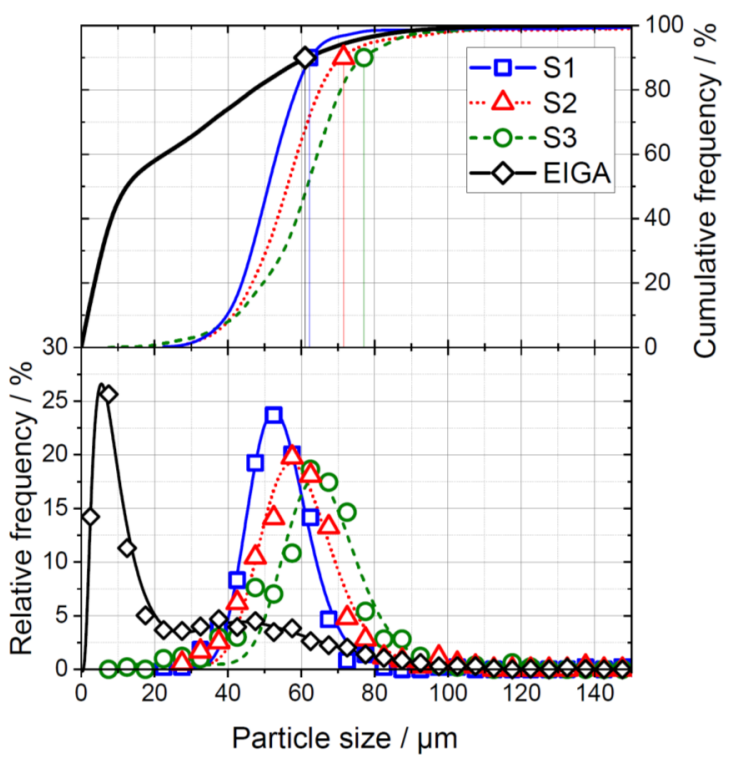

(a)

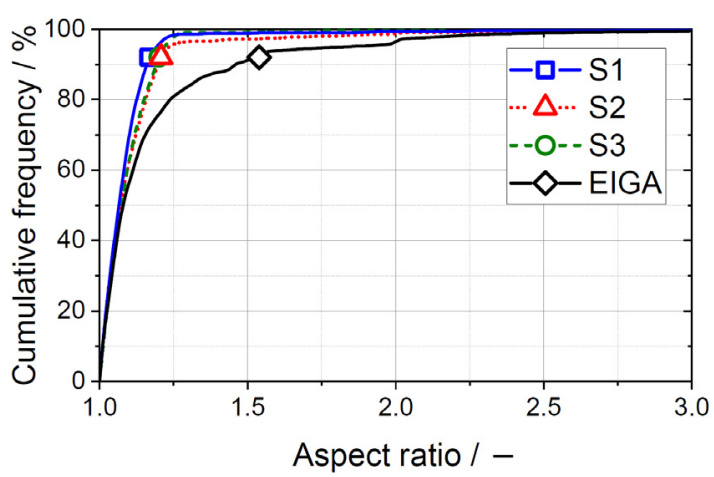

(b)

Figure 3. Particle size distribution (a) and aspect ratio distribution (b) of powders produced with UA (S1 to S3) and EIGA.

The microstructures of the alloy after arc melting and UA are depicted in Figure 4a,c. Figure 4a shows the microstructure in the as-cast state right after arc melting. As previously reported in Refs. [9,11], the lamellar eutectic colonies consisted of Mo-rich solid solution $\mathrm{Mo}_{\mathrm{ss}}$ (bright contrast) and ( $\left.\mathrm{Ti}, \mathrm{Mo}\right)_{5} \mathrm{Si}_{3}$ (dark contrast). The eutectic colonies were surrounded by a degenerated eutectic microstructure, and some primary solidification of $(\mathrm{Ti}, \mathrm{Mo})_{5} \mathrm{Si}_{3}$ occurred, both of which were characteristic of the present alloy. The rapid cooling during atomization fundamentally changed the microstructure as seen in Figure 4c. Extremely fine (Ti,Mo) $)_{5} \mathrm{Si}_{3}$ lamellae with an average interlamellar spacing of only $(30 \pm 8)$ $\mathrm{nm}$ were surrounded by a $\mathrm{Mo}_{\mathrm{ss}}$ matrix. The overview images in Figure $4 \mathrm{a}, \mathrm{c}, \mathrm{e}$ show that the UA powder microstructure was so fine-scaled in comparison to the as-cast condition that the information on the phase distribution can only be drawn from the further magnified inset. The very homogeneous microstructure did not exhibit clear eutectic colonies, and the nucleation of primary $\mathrm{Ti}_{5} \mathrm{Si}_{3}$ was suppressed due to significant supercooling. 


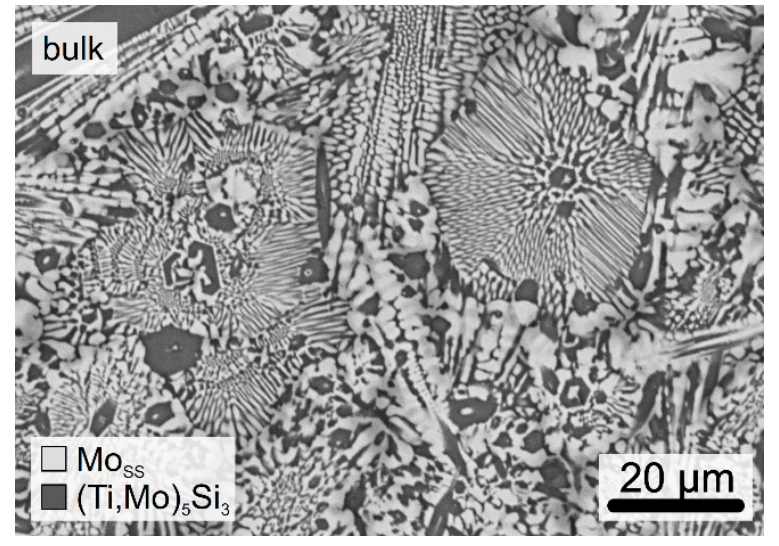

(a)

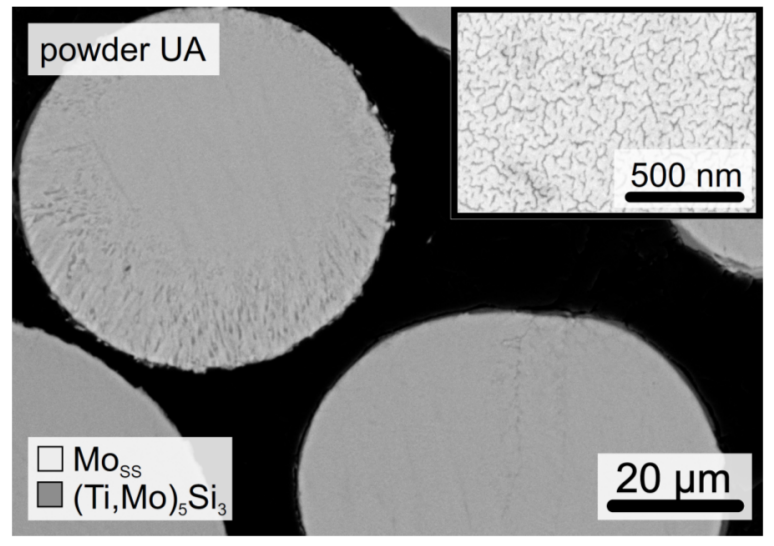

(c)

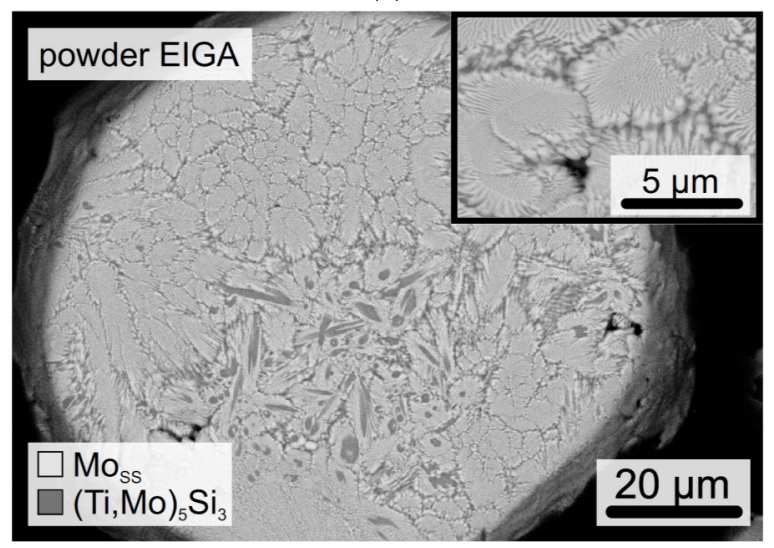

(e)

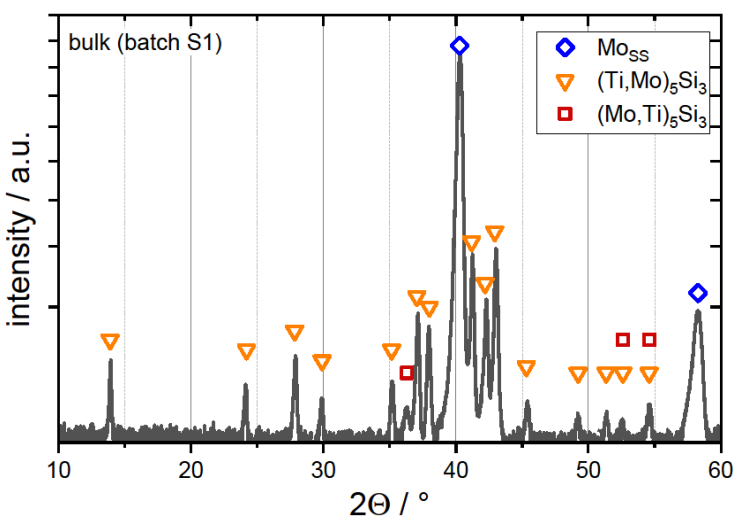

(b)

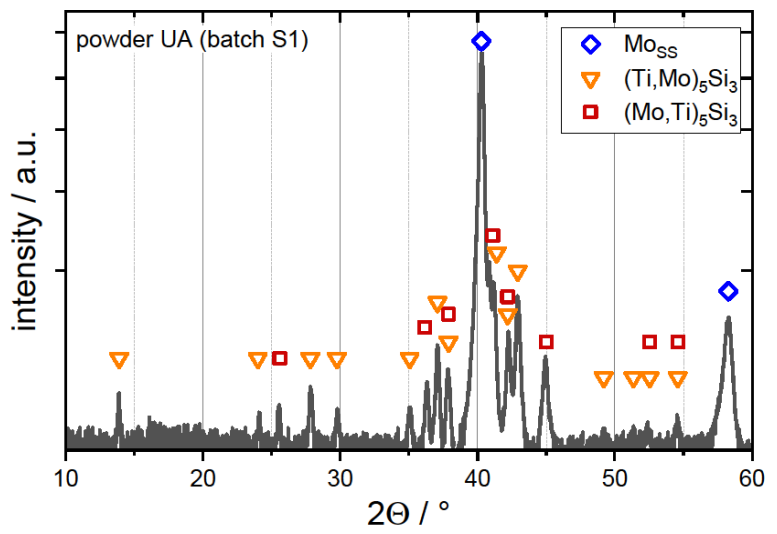

(d)

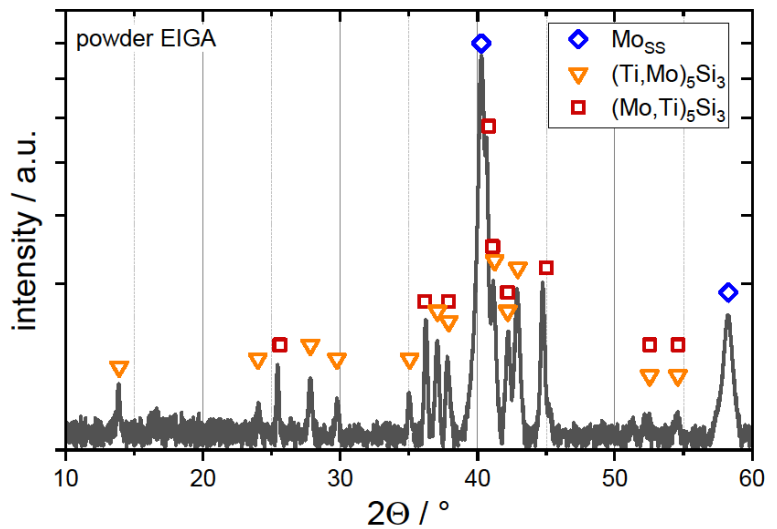

(f)

Figure 4. SEM BSE micrographs of the microstructures $(\mathbf{a}, \mathbf{c}, \mathbf{e})$ and XRD patterns $(\mathbf{b}, \mathbf{d}, \mathbf{f})$ of the as-cast material $(\mathbf{a}, \mathbf{b})$, UA powder $(\mathbf{c}, \mathbf{d})$, and EIGA powder $(\mathbf{e}, \mathbf{f})$. The intensity axes of the XRD patterns are plotted with square root scale in order to improve visibility of low-intensity Bragg peaks.

The presence of the two phases, namely, the body-centred cubic crystal structure $\mathrm{Mo}_{\mathrm{ss}}$ (W prototype) and the hexagonal ( $\mathrm{Ti}, \mathrm{Mo})_{5} \mathrm{Si}_{3}\left(\mathrm{Mn}_{5} \mathrm{Si}_{3}\right.$ prototype) were confirmed by XRD analyses shown in Figure $4 \mathrm{~b}, \mathrm{~d}$. $(\mathrm{Ti}, \mathrm{Mo})_{5} \mathrm{Si}_{3}$ indicates that Ti lattice sites were substituted with Mo atoms while still remaining in the hexagonal structure. In the XRD pattern, there were some additional peaks, e.g., at $36.3^{\circ}$ for the bulk material and $25.6^{\circ}, 36.3^{\circ}$, and $41.1^{\circ}$ for the UA powders, which were indicative of tetragonal (Mo, $\mathrm{Ti}_{5} \mathrm{Si}_{3}\left(\mathrm{~W}_{5} \mathrm{Si}_{3}\right.$ prototype). In any case, no evidence of $\left(\mathrm{Mo}, \mathrm{Ti}_{5}\right)_{5} \mathrm{Si}_{3}$ was found in the BSE micrographs. 
Changes in the chemical composition of the alloys due to the atomization process were not found. ICP-OES analyses, depicted in Figure 5a, showed that the target composition of the alloy was well met by the arc-melting step. Additionally, there were no significant changes in composition in the powder state, suggesting that there was no vaporization of certain elements due to the atomization process for any of the three UA batches. The $\mathrm{O}$ contents are visualized in Figure $5 \mathrm{~b}$. In the as-cast state, the $\mathrm{O}$ content of all three batches was about $460 \mathrm{wt} . \mathrm{ppm}$. O picked up during the atomization process and powder handling lay in the order of about 900 wt.ppm, leading to O contents in the powders of S1: $(1450 \pm 20)$ wt.ppm, S2: $(1330 \pm 10)$ wt.ppm, and S3: $(1280 \pm 30)$ wt.ppm. These results were compared to literature data on Mo- and Ti-based alloys manufactured by various techniques (Figure 5c).

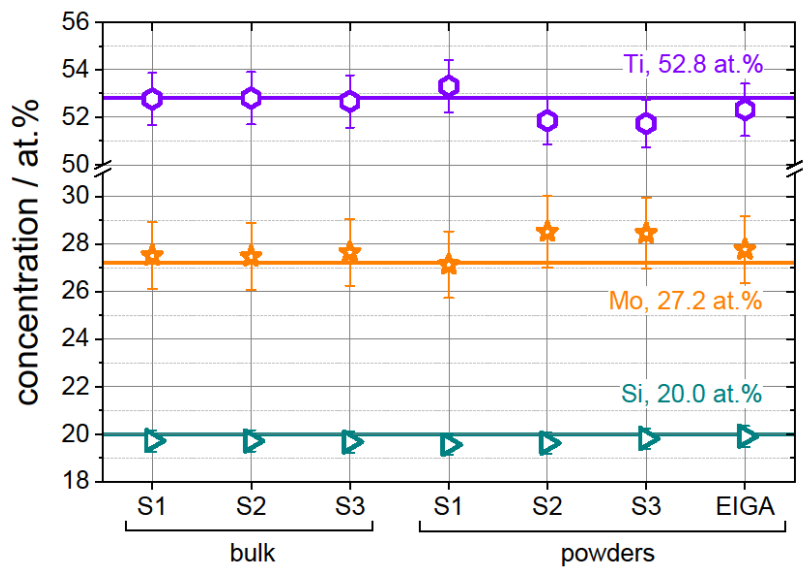

(a)

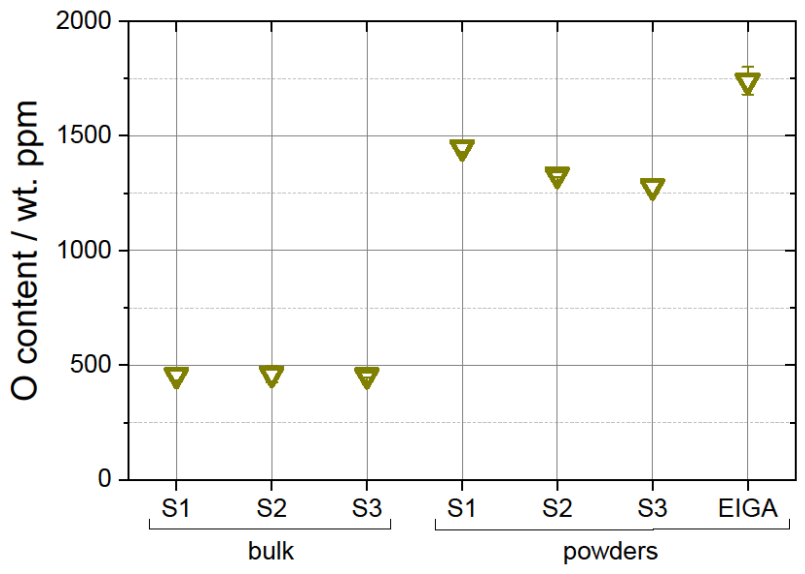

(b)

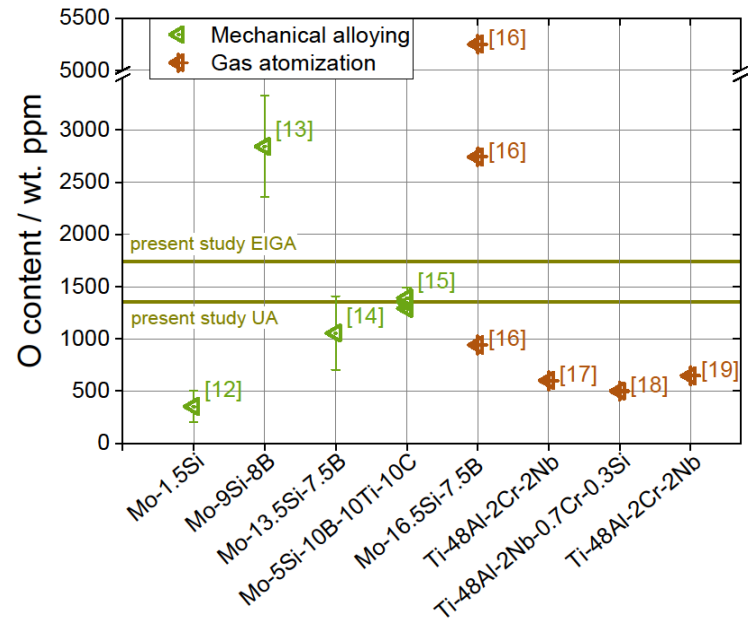

(c)

Figure 5. Alloy composition by ICP-OES in the arc-melted as-cast state (bulk) and after atomization (a), O contents by CGHE (b), and O contents of powders of several Mo- and Ti-containing powders reported in the literature [12-19] (c).

\subsection{EIGA Powder}

Eighteen $\mathrm{kg}$ of powder were produced, $53 \mathrm{wt} . \%$ of which were particles with diameters $<100 \mu \mathrm{m}$. A topography image of the EIGA powder particles is shown in Figure $2 \mathrm{~b}$. There were satellite particles observed as well as irregularly shaped particles. The particles covered a wider range of sizes compared to the UA powder. The respective size distribution is depicted with black symbols in Figure 3a. The particle size exhibited a bimodal distribution with a large peak at about $10 \mu \mathrm{m}$ and a smaller peak at around $40 \mu \mathrm{m}$. In this case, the proportion of fine particles was high. Of the particles, $56 \%$ were fine particles 
smaller than $20 \mu \mathrm{m}$, and $24 \%$ were in the range of 40 to $80 \mu \mathrm{m}$. The cumulative frequency of the particles' aspect ratio is depicted in Figure $3 \mathrm{~b}$. Although the particles had slightly higher aspect ratios than the UA powder particles, $90 \%$ of the particles still possessed a sphericity of better than 1.5 .

Through atomization, a two-phase $\mathrm{Mo}_{\mathrm{ss}}$ and $(\mathrm{Ti}, \mathrm{Mo})_{5} \mathrm{Si}_{3}$ microstructure was achieved, which was confirmed by SEM and XRD analyses (cf. Figure 4e,f). The micrograph showed a fine scaled eutectic microstructure with clearly contrasted eutectic colonies and some primary $(\mathrm{Ti}, \mathrm{Mo})_{5} \mathrm{Si}_{3}$. Compared to the UA powder, the eutectic lamellae of the EIGA powder were coarser, which implies a slower cooling rate of the melt droplets in the EIGA.

ICP-OES analysis of the powder confirmed that the target composition Mo-20Si-52.8Ti was met. The $O$ content of the EIGA powders was $1740 \pm 60$ wt.ppm and therefore was 200-400 wt.ppm higher than for the UA powders.

\subsection{Powder Consolidation}

Quality assessment of the powders was done on FAST bulk samples as well since not only chemical information by EDX is accurate on flat homogenous samples, but phase formation (which might be affected by impurities) is also closer to equilibrium. This can be seen, e.g., in the absence of distinct $\mathrm{Ti}_{5} \mathrm{Si}_{3}$ phase regions in the UA powder compared (Figure $4 \mathrm{~d}$ ) to the expected phases in the consolidated case (Figure 6b).

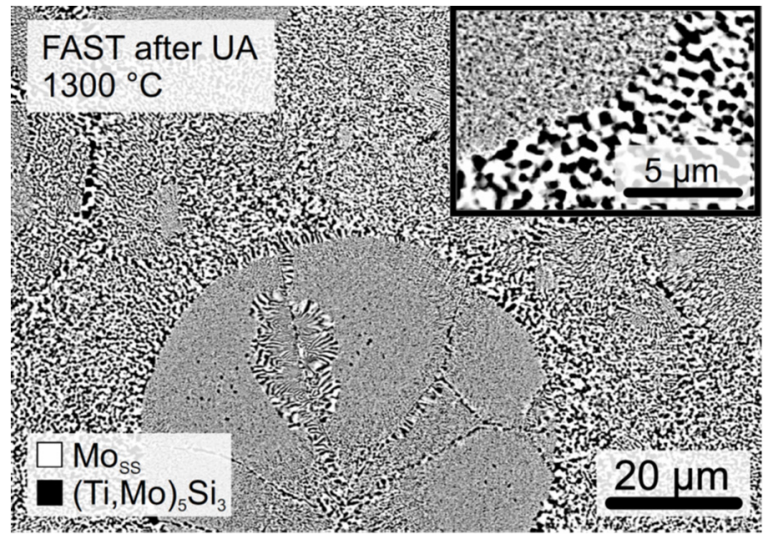

(a)

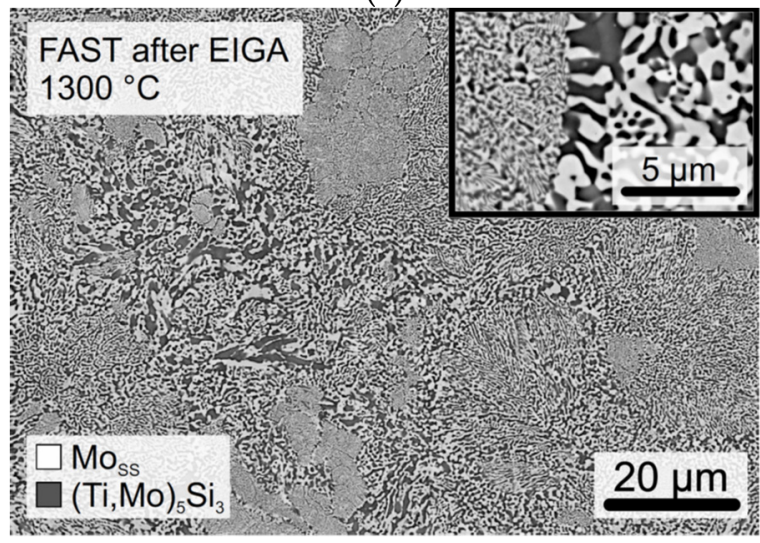

(c)

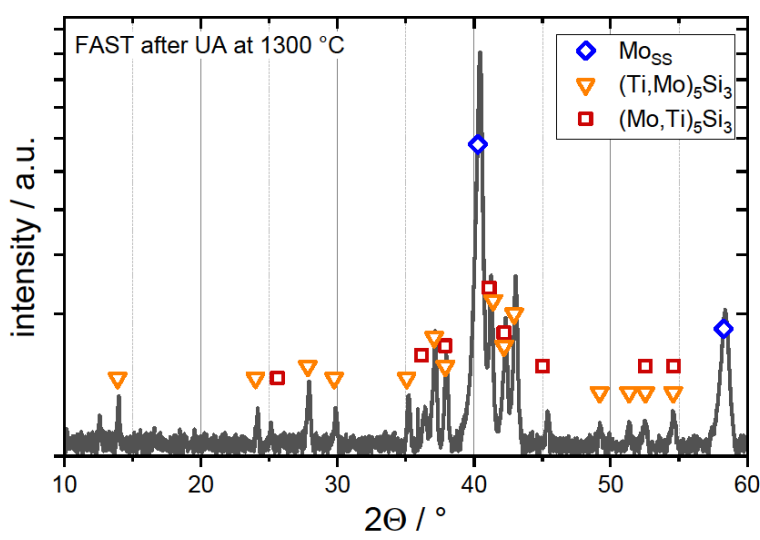

(b)

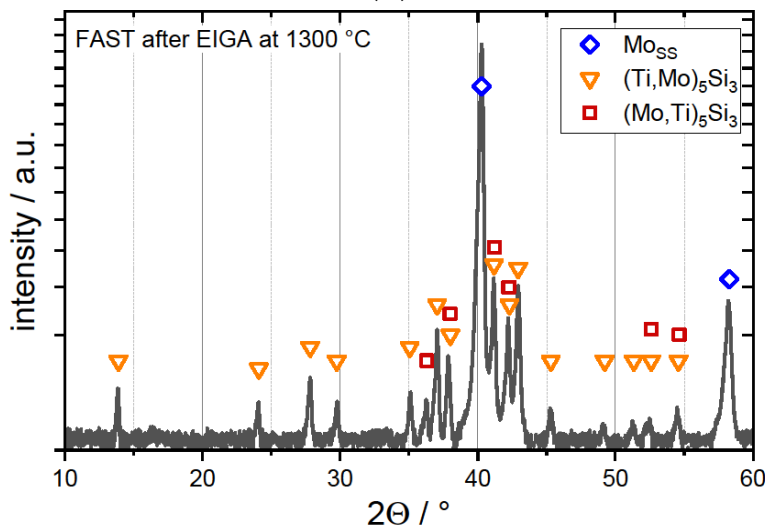

(d)

Figure 6. SEM BSE micrographs of the microstructures $(\mathbf{a}, \mathbf{c})$ and XRD patterns $(\mathbf{b}, \mathbf{d})$ of the consolidated materials from UA powder $(\mathbf{a}, \mathbf{b})$ and EIGA powder $(\mathbf{c}, \mathbf{d})$.

Micrographs of the consolidated UA and EIGA powders are displayed in Figure 6a,c. The XRD patterns revealed the expected phases of $\mathrm{Mo}_{\mathrm{ss}}$ and $(\mathrm{Ti}, \mathrm{Mo})_{5} \mathrm{Si}_{3}$ in Figure $6 \mathrm{~b}, \mathrm{~d}$. After the FAST process, some of the former powder particles from UA were still apparent in the microstructure by significantly finer lamellar spacing sharply separated from inter- 
particle diffusion region. However, even in the inter-particle zones resulting from the sintering process, the microstructure was much finer than in the as-cast state. Consolidation at $1300{ }^{\circ} \mathrm{C}$, which corresponded to a homologous temperature $\mathrm{T}_{\mathrm{h}}=\mathrm{T} / \mathrm{T}_{\mathrm{S}}=0.75$, with $\mathrm{T}_{\mathrm{S}}$ being the solidus temperature, produced a fully dense sample, whereas a consolidation temperature of $1200^{\circ} \mathrm{C}$, corresponding to a $\mathrm{T}_{\mathrm{h}}$ of 0.7 , led to a residual porosity of $(0.6 \pm 0.2)$ vol.\%. The consolidation showed that UA also provides potential for further microstructure tailoring by powder and bulk processing due to the strong non-equilibrium state of the powder microstructure. Usually, mechanical alloying is used in case of refractory metalbased alloys to achieve such non-equilibrium conditions but with the drawback of much higher impurity levels.

The consolidated microstructure of the EIGA powder appeared fine-scaled as well. The former spherical particles can still be recognized, but separation from the inter particle diffusion region was less pronounced compared to the UA powder consolidated under identical conditions. Even though the sample was expected to be fully dense based on the experiment on the UA powders, the consolidated EIGA powder still showed some $(<0.1 \mathrm{vol} . \%)$ porosity with pores in the order of $20-40 \mu \mathrm{m}$ in diameter.

The microstructures of the consolidated samples of the UA and EIGA powders differed mainly regarding the clear separation of the former powder particles in the UA sample and the less distinct former particles in the EIGA sample due to their smaller sizes and resulting larger surface areas. The resulting microstructures in the diffusion zones of the consolidated samples showed similar length scales for UA and EIGA, although the UA powder microstructure was much finer before.

\section{Discussion}

The principle of metal powder production through UA has been known for a long time already and has at first been applied to elements and alloys with low liquidus temperatures, such as $\mathrm{Pb}, \mathrm{Sb}$, or Sn-Zn alloys, for example, for solders [20-22]. Recent studies have also successfully applied a UA approach to materials with higher liquidus temperatures such as steels [23,24], Ni-Mn-Ga, Ti alloys, and Fe-Cr-Mn-Ni high entropy alloys [23]. In the experiment of Alavi and Harimkar [24], a laser beam melts the bulk substrate material, which is screwed on top of a ultrasonic probe. However, for brittle refractory metal-based materials, this setup is difficult to realize since the substrate has to be machined with a screw thread. In the approach of Żrodowsky et al. [23], the setup is similar to the one discussed in this study, but it used a material feedstock that is inductively molten before being applied onto the sonotrode platform. In contrast, the commercially available device we presented can be easily incorporated in a standard, lab-based arc-melting route to produce tailored alloy composition feedstock. To our knowledge, yet all UA approaches for the production of metal powders used unique custom-made laboratory equipment, and no studies have been done on this now commercially available solution.

The narrow size distribution of the UA powder particles obtained in the present study suggests that the droplet formation was largely controlled by the mechanisms of the capillary model as described by Eisenmenger [25] and not by the cavitation theory introduced by Söllner [26]. The latter applies for very high ultrasonic intensities, which lead to spattered particles, but can be well prevented through keeping the ultrasonic intensity below the cavitation limit [27]. However, spherical particles with uniform size distributions form from the excitation of standing surface waves on a wetted vibrating surface. With increasing intensity of the vibration, the maxima of the standing waves pile up into thin columns until they become hydrodynamically unstable and uniform droplets detach at the tips [27]. Furthermore, the decisive parameters for efficient and successful atomization of the liquid are (i) a sufficiently large excitation amplitude and (ii) a sufficiently low viscosity of the melt [22]. Therefore, the energy input to the melt pool provided by the plasma arc must be great enough so that the viscosity of the superheated melt is sufficiently low for atomization. 
In terms of size distribution, sphericity, and particle density, the UA powders are well suited for AM and reveal the feasibility of the method for initial stages of alloy powder research. In the present state, feed rod material is limited to a maximum diameter of $10 \mathrm{~mm}$ or a wire of max. $1.6 \mathrm{~mm}$ in diameter. For the processing of arc-melted rod material, the UA process is discontinuous since sufficiently small melt drops need to be established in superheated condition one after another. Hence, material throughput in UA using rod type material is limited in the present state. Input material that can be manufactured in the form of wire coils can be atomized continuously and could even produce powder quantities that are directly feasible for AM. Lierke et al. [22] were able to produce lead powder with an UA setup at a powder yield of 40-50 1/h, which exceeded the available conventional atomization methods. The two main parameters to increase material throughput for UA are increasing frequencies and the ratio of melt pool surface area to volume [22].

Nevertheless, the results from the EIGA process with the PM-produced electrode showed that the established industrial process can be modified to produce refractory metal alloy powders in sufficient quantity. The process can be adapted to produce various compositions. The in-situ alloy formation at the induction-melted electrode tip obviously provides enough mixing to obtain the desired two-phase eutectic microstructure. The occurrence of hollow particles is typical of gas atomization processes like EIGA due to the splitting of the melt flow by the high impact of the atomization gas. They remain present as component porosity in the solid part after sintering or fusion AM processes [7,14,28-30] and impair the mechanical properties. As far as the component porosity of sintered or printed components are concerned, dense powder particles such as those produced during UA by the aforementioned detachment from standing waves on the liquid surface are desired. For both processing routes, the feasibility of the concept was proven by obtaining the desired composition.

With regards to the evaluation of the $\mathrm{O}$ contents, there is no industrial standard existing for Mo-20Si-52.8Ti (at.\%) powders for AM. Due to the high Ti content, the industrial standard for Ti-6Al-4V may provide an indication of an acceptable upper limit. ASTM F2924-14 [31] specifies that AM parts of Ti-6Al-4V are allowed up to $0.2 \mathrm{wt}$ \% $\mathrm{O}$ in the as-built part. Since there will be some $\mathrm{O}$ pickup in any build process, $\mathrm{O}$ contents below $0.15 \mathrm{wt} . \%$ are considered necessary for Ti-6Al-4V powders to prevent embrittlement of the final part [32].

The AM of Mo-based alloys on the other hand has not yet been studied extensively. Therefore, data on acceptable $\mathrm{O}$ contents are mainly available from Mo alloys processed through conventional PM routes. According to a recent review, Mo-based PM alloys typically contain between 100 wt.ppm and 3000 wt.ppm O [8]. Alloys with large amounts of Mo solid solution should thrive for $\mathrm{O}$ contents towards the lower end of that range to avoid embrittlement. Regarding AM of Mo-based alloys, feasibility studies have been conducted on Mo-TiC [33], Mo-Si-B [14,16], and Mo-Si-B-TiC [15,34] alloys. Fichtner et al. [16], who studied laser powder bed fusion (LPBF) of Mo-Si-B powders, reported on powder $\mathrm{O}$ contents. The gas-atomized Mo-16.5Si-7.5B powder originally contained 940 wt.ppm $\mathrm{O}$ and exhibited an O pick-up up to 5251 wt.ppm. by thermal exposure (cf. Figure 5c). In their experiments, only extensive efforts to reduce impurities and moisture lead to crack-free samples. Zhou et al. [15] tracked the oxygen content of the Mo-Si-B-TiC, which was used for LPBF. In the ball-milled powder state, they reported on $1290 \mathrm{wt}$.ppm O. Oxygen pickup during LPBF leading to 1350 wt.ppm $\mathrm{O}$ in the as-built samples, and the $\mathrm{O}$ content increased to 1380 wt.ppm after subsequent hot isostatic pressing.

For Mo-20Si-52.8Ti (at.\%), the critical level of O content to obtain crack-free AM samples might be higher than what Fichtner et al. [16] reported for Mo-16.5Si-7.5B due to the substantial Ti amount of approximately 40 at.\% in $\mathrm{Mo}_{\mathrm{ss}}$ [11] but certainly not above the limits for conventional AM Ti-based alloys. If ASTM F2924-14 is considered as a guideline for Mo-20Si-52.8Ti (at.\%), the UA powders lie well below the $0.2 \mathrm{wt} . \%$ limit and would allow for an $\mathrm{O}$ uptake of 0.05 wt.\% during an AM process, whereas the EIGA powder had only a $0.03 \mathrm{wt} \%$ margin to the $0.2 \mathrm{wt}$ \% limit [31]. In the laboratory setup, this could 
only be further improved by using raw elements of higher purity in conjunction with a process gas of higher purity. The objective of the present study focused on powders made from materials suffering from sufficient low-temperature ductility. With regards to prospective AM techniques, electron beam powder bed fusion (EB-PBF), rather than laser powder bed fusion (L-PBF), can be considered as the most promising method of choice due to usually higher heating temperatures and homogeneity of pre-heating [1]. The necessary particle size distribution for EBM was met by our method [1]. Considering all the properties studied, the Mo-Si-Ti powders, which were produced for the first time with both UA and EIGA, exhibited characteristics that fulfilled all necessary requirements for AM trials.

\section{Conclusions}

- Powders of Mo-20Si-52.8Ti (at.\%) were produced for the first time with an UA process at laboratory-scale, and an EIGA process for upscaling to large-scale industrial quantities was used.

- Both processes can be adapted to process refractory metal alloys of various compositions.

- Quick adaptation to various alloy compositions makes UA well suited for flexible alloy powder development.

- With both processes, powders were produced that fulfil the necessary requirements for AM.

Author Contributions: Conceptualization, F.H., A.K., K.R., M.A. and M.H.; data curation, F.H.; formal analysis, F.H., A.K., D.S., S.S. and M.A.; funding acquisition, A.P. and M.H.; investigation, F.H., D.S., S.S., S.O., K.R. and M.A.; methodology, A.K., D.S., S.S., S.O., K.R. and M.A.; project administration, K.R.; resources, A.P. and M.H.; supervision, A.K., K.R. and M.H.; validation, F.H., D.S. and S.S.; visualization, F.H. and A.K.; writing-original draft, F.H. and A.K.; writing-review \& editing, A.K., D.S., S.S., S.O., K.R., M.A., A.P. and M.H. All authors have read and agreed to the published version of the manuscript.

Funding: We gratefully acknowledge financial support by the Deutsche Forschungsgemeinschaft (DFG) within the framework of GRK 2561 MatCom-ComMat.

Institutional Review Board Statement: Not applicable.

Informed Consent Statement: Not applicable.

Data Availability Statement: The data presented in this study are available on request from the corresponding author.

Acknowledgments: The authors acknowledge the chemical analysis by ICP-OES conducted at the Institute for Applied Materials (IAM-AWP), Karlsruhe Institute of Technology (KIT). This work was partly carried out with the support of the Karlsruhe Nano Micro Facility (KNMF, www.knmf.kit.edu), a Helmholtz Research Infrastructure at Karlsruhe Institute of Technology (KIT, www.kit.edu). We acknowledge support by the KIT-Publication Fund of the Karlsruhe Institute of Technology (KIT). We thank Angela Ganza for experimental support.

Conflicts of Interest: The authors declare no conflict of interest.

\section{References}

1. Körner, C. Additive manufacturing of metallic components by selective electron beam melting-A review. Int. Mater. Rev. 2016, 61,361-377. [CrossRef]

2. Gunasekaran, J.; Sevvel, P.; Solomon, I.J. Metallic materials fabrication by selective laser melting: A review. Mater. Today Proc. 2021, 37, 252-256. [CrossRef]

3. Lewandowski, J.J.; Seifi, M. Metal Additive Manufacturing: A Review of Mechanical Properties. Annu. Rev. Mater. Res. 2016, 46, 151-186. [CrossRef]

4. Vock, S.; Klöden, B.; Kirchner, A.; Weißgärber, T.; Kieback, B. Powders for powder bed fusion: A review. Prog. Addit. Manuf. 2019, 4, 383-397. [CrossRef]

5. Gombola, C.; Kauffmann, A.; Geramifard, G.; Blankenburg, M.; Heilmaier, M. Microstructural Investigations of Novel High Temperature Alloys Based on NiAl-(Cr,Mo). Metals 2020, 10, 961. [CrossRef] 
6. Jehanno, P.; Kestler, H.; Venskutonis, A.; Boning, M.; Heilmaier, M.; Bewlay, B.; Jackson, M. Assessment of a powder metallurgical processing route for refractory metal silicide alloys. Met. Mater. Trans. A 2005, 36, 515-523. [CrossRef]

7. Gerling, R.; Clemens, H.; Schimansky, F. Powder Metallurgical Processing of Intermetallic Gamma Titanium Aluminides. Adv. Eng. Mater. 2004, 6, 23-38. [CrossRef]

8. Perepezko, J.H.; Krüger, M.; Heilmaier, M. Mo-Silicide Alloys for High-Temperature Structural Applications. Mater. Perform. Charact. 2021, 10, 20200183. [CrossRef]

9. Schliephake, D.; Kauffmann, A.; Cong, X.; Gombola, C.; Azim, M.; Gorr, B.; Christ, H.-J.; Heilmaier, M. Constitution, oxidation and creep of eutectic and eutectoid Mo-Si-Ti alloys. Intermetallics 2019, 104, 133-142. [CrossRef]

10. ALD Brochure. Available online: https://www.ald-vt.com/wp-content/uploads/2018/01/Metal_Additive_Manufacturing.pdf (accessed on 12 October 2021).

11. Obert, S.; Kauffmann, A.; Seils, S.; Schellert, S.; Weber, M.; Gorr, B.; Christ, H.-J.; Heilmaier, M. On the chemical and microstructural requirements for the pesting-resistance of Mo-Si-Ti alloys. J. Mater. Res. Technol. 2020, 9, 8556-8567. [CrossRef]

12. Saage, H.; Krüger, M.; Sturm, D.; Heilmaier, M.; Schneibel, J.; George, E.; Heatherly, L.; Somsen, C.; Eggeler, G.; Yang, Y. Ductilization of Mo-Si solid solutions manufactured by powder metallurgy. Acta Mater. 2009, 57, 3895-3901. [CrossRef]

13. Krüger, M.; Franz, S.; Saage, H.; Heilmaier, M.; Schneibel, J.; Jéhanno, P.; Böning, M.; Kestler, H. Mechanically alloyed Mo-Si-B alloys with a continuous $\alpha$-Mo matrix and improved mechanical properties. Intermetallics 2008, 16, 933-941. [CrossRef]

14. Schmelzer, J.; Rittinghaus, S.-K.; Weisheit, A.; Stobik, M.; Paulus, J.; Gruber, K.; Wessel, E.; Heinze, C.; Krüger, M. Printability of gas atomized Mo-Si-B powders by laser metal deposition. Int. J. Refract. Met. Hard Mater. 2019, 78, 123-126. [CrossRef]

15. Zhou, W.; Tsunoda, K.; Nomura, N.; Yoshimi, K. Effect of hot isostatic pressing on the microstructure and fracture toughness of laser additive-manufactured MoSiBTiC multiphase alloy. Mater. Des. 2020, 196, 109132. [CrossRef]

16. Fichtner, D.; Schmelzer, J.; Yang, W.; Heinze, C.; Krüger, M. Additive manufacturing of a near-eutectic Mo-Si-B alloy: Processing and resulting properties. Intermetallics 2021, 128, 107025. [CrossRef]

17. Biamino, S.; Penna, A.; Ackelid, U.; Sabbadini, S.; Tassa, O.; Fino, P.; Pavese, M.; Gennaro, P.; Badini, C. Electron beam melting of Ti-48Al-2Cr-2Nb alloy: Microstructure and mechanical properties investigation. Intermetallics 2011, 19, 776-781. [CrossRef]

18. Baudana, G.; Biamino, S.; Klöden, B.; Kirchner, A.; Weißgärber, T.; Kieback, B.; Pavese, M.; Ugues, D.; Fino, P.; Badini, C. Electron Beam Melting of Ti-48Al-2Nb-0.7Cr-0.3Si: Feasibility investigation. Intermetallics 2016, 73, 43-49. [CrossRef]

19. Schwerdtfeger, J.; Körner, C. Selective electron beam melting of Ti-48Al-2Nb-2Cr: Microstructure and aluminium loss. Intermetallics 2014, 49, 29-35. [CrossRef]

20. Wisutmethangoon, S.; Plookphol, T.; Sungkhaphaitoon, P. Production of SAC305 powder by ultrasonic atomization. Powder Technol. 2011, 209, 105-111. [CrossRef]

21. Sheikhaliev, S.M.; Popel, S.I. Production of metal powders by ultrasonic atomization of melts. Powder Met. Met. Ceram. 1983, 22, 793-798. [CrossRef]

22. Lierke, E.; Grießhammer, G. The formation of metal powders by ultrasonic atomization of molten metals. Ultrasonics 1967, 5, 224-228. [CrossRef]

23. Żrodowski, Ł.; Wróblewski, R.; Choma, T.; Morończyk, B.; Ostrysz, M.; Leonowicz, M.; Łacisz, W.; Błyskun, P.; Wróbel, J.; Cieślak, G.; et al. Novel Cold Crucible Ultrasonic Atomization Powder Production Method for 3D Printing. Materials 2021, $14,2541$. [CrossRef]

24. Alavi, S.H.; Harimkar, S.P. Ultrasonic vibration-assisted laser atomization of stainless steel. Powder Technol. 2017, 321, 89-93. [CrossRef]

25. Eisenmenger, W. Dynamic properties of the surface tension of water and aqueous solutions of surface active agents with standing capillary waves in the frequency range from $10 \mathrm{kc} / \mathrm{s}$ to $1.5 \mathrm{Mc} / \mathrm{s}$. Acta Acust. United Acust. 1959, 9, 327-340.

26. Söllner, K. The mechanism of the formation of fogs by ultrasonic waves. Trans. Faraday Soc. 1936, 32, 1532-1536. [CrossRef]

27. Reimann, U.; Pohlman, R. Optimierung der Vernebelung von Flüssigkeiten mit Ultraschall unter Berücksichtigung der Probleme bei höheren Frequenzen. Forsch. Ing. 1976, 42, 1-7. [CrossRef]

28. Ahsan, M.N.; Pinkerton, A.; Moat, R.; Shackleton, J. A comparative study of laser direct metal deposition characteristics using gas and plasma-atomized Ti-6Al-4V powders. Mater. Sci. Eng. A 2011, 528, 7648-7657. [CrossRef]

29. Helmer, H.E.; Körner, C.; Singer, R.F. Additive manufacturing of nickel-based superalloy Inconel 718 by selective electron beam melting: Processing window and microstructure. J. Mater. Res. 2014, 29, 1987-1996. [CrossRef]

30. Iebba, M.; Astarita, A.; Mistretta, D.; Colonna, I.; Liberini, M.; Scherillo, F.; Pirozzi, C.; Borrelli, R.; Franchitti, S.; Squillace, A. Influence of Powder Characteristics on Formation of Porosity in Additive Manufacturing of Ti-6Al-4V Components. J. Mater. Eng. Perform. 2017, 26, 4138-4147. [CrossRef]

31. ASTM F2924-14(2021). Standard Specification for Additive Manufacturing Titanium-6 Aluminum-4 Vanadium with Powder Bed Fusion; ASTM International: West Conshohocken, PA, USA, 2021.

32. Sun, P.; Fang, Z.Z.; Zhang, Y.; Xia, Y. Review of the Methods for Production of Spherical Ti and Ti Alloy Powder. JOM 2017, 69, 1853-1860. [CrossRef]

33. Rock, C.; Lara-Curzio, E.; Ellis, B.; Ledford, C.; Leonard, D.N.; Kannan, R.; Kirka, M.; Horn, T. Additive Manufacturing of Pure Mo and Mo + TiC MMC Alloy by Electron Beam Powder Bed Fusion. JOM 2020, 72, 4202-4213. [CrossRef]

34. Zhou, W.; Sun, X.; Tsunoda, K.; Kikuchi, K.; Nomura, N.; Yoshimi, K.; Kawasaki, A. Powder fabrication and laser additive manufacturing of MoSiBTiC alloy. Intermetallics 2019, 104, 33-42. [CrossRef] 